Article

\title{
Genetic Diversity among Selected Medicago sativa Cultivars Using Inter-Retrotransposon-Amplified Polymorphism, Chloroplast DNA Barcodes and Morpho-Agronomic Trait Analyses
}

\author{
Abdelfattah Badr ${ }^{1} \mathbb{D}$, Nahla El-Sherif ${ }^{2,3} \mathbb{D}$, Sara Aly ${ }^{2}$, Shafik D. Ibrahim ${ }^{4}$ (D) \\ and Mohamed Ibrahim $2, *$ (D) \\ 1 Botany and Microbiology Department, Faculty of Science, Helwan University, Cairo 11790, Egypt; \\ abadr@science.helwan.edu.eg \\ 2 Botany Department, Faculty of Science, Ain Shams University, Cairo 11566, Egypt; \\ elsherif.nahla@sci.asu.edu.eg (N.E.-S.); saraaly@sci.asu.edu.eg (S.A.) \\ 3 Biology Department, Faculty of Science, Taibah University, Madinah 344, Saudi Arabia \\ 4 Agricultural Genetic Engineering Research Institute (AGERI), Agricultural Research Center (ARC), \\ Giza 12619, Egypt; shafikdarwish2014@gmail.com \\ * Correspondence: m.shehata@sci.asu.edu.eg
}

Received: 16 June 2020; Accepted: 27 July 2020; Published: 5 August 2020

\begin{abstract}
Alfalfa (Medicago sativa L.) is a major forage crop of family Fabaceae and is frequently cultivated in Egypt. The present study is concerned with the genetic discrimination of fifteen alfalfa cultivars from three different countries (Egypt, Australia, and USA) using two molecular approaches: inter-retrotransposon-amplified polymorphism (IRAP) markers and two chloroplast DNA barcodes mat $\mathrm{K}$ and the $t r n \mathrm{H}$ in addition to the analysis of fifteen morpho-agronomic traits. The genetic relatedness, based on analysis of IRAP marker polymorphism and produced using eleven primers by clustering via principal component analysis (PCA) and multivariate heatmap biostatistical methods differentiated the two Egyptian cultivars EGY1-Ismailia1 and EGY2-Nubaria1 from the three Australian and seven American cultivars, with some distinction of the cv. USA6-SW9720 and cv. AUS4-SuperFast. The results were also supported by the sequence analysis of the matK and the $\operatorname{trn} \mathrm{H}$ genes on the genetic relatedness between eight cultivars. Moreover, it might be suggested that breeding lines from $M$. sativa cultivars may provide novel insights and a better understanding of the domestication of $M$. sativa genetic diversity. The classification of the eight cultivars, as revealed by morpho-agronomic traits, confirmed the close genetic relationship between the two Egyptian cultivars and indicated some resemblance between them and the AUS2-Siri Nafa, whereas the two American cultivars, USA1-Super supreme and USA4-Cuf101, were clearly isolated from a cluster of other three cultivars USA7-SW9628, USA8-Magna901, and USA9-Perfect. The results are useful sources of genetic information for future breeding programs in crop development and open new possibilities of producing M. sativa lines harboring high forage quality, productivity, and resistance to biotic and abiotic stresses.
\end{abstract}

Keywords: Medicago sativa L.; genetic diversity; molecular markers; DNA barcoding; IRAP; matK; trnH

\section{Introduction}

Alfalfa (Medicago sativa L.), known as alfalfa and lucerne, is a major important cultivated forage legume crop that was originated in the Caucasus region, and plays a significant role in agricultural sustainability [1]. It is one of the worldwide planted legume crops for forage sources cause of its high 
biomass yield, highly nutritious preserved forage (viz, pasture, hay, or silage) and wide adaptability to environments. Also, for sustainable cropping systems alfalfa has worthy benefits because of its root formation and perennial life cycle restrict soil erosion. Alfalfa root system forms a symbiosis with Sinorhizobium meliloti, the soil bacterium. The latter bacterium species fixes atmospheric nitrogen for increasing soil fertility [2]. Alfalfa has a genome size of 800-1000 Mbp [3] and exists at two polyploids levels; diploid: $2 x=16$ and autotetraploid: $4 x=32$, where letter " $x$ " is used to define the ploidy level. Alfalfa is cross pollinated and propagated by seeds [1,4]. Like other crops, agronomic and quality traits in alfalfa may be improved using plant materials having rich genetic variation and analysis of morpho-agronomic traits and using marker selected breeding (MSB). Knowledge on the genetic diversity and relatedness between alfalfa cultivars and landraces is limited, but necessary for breeding new genotypes of alfalfa with improved crop quality. In northern Italy, landraces geographically close or of the same commercial ecotype tend to show a greater similarity and landraces are superior to elite varieties of alfalfa in all traits except autumn dormancy and number of florets per inflorescence [5]. Alfalfa germplasm collection was evaluated by multivariate analysis and recorded considerable variation in phenotypic traits [6]. The efficiency of phenotypic and RAPD markers was estimated for diversity assessment of alfalfa accessions from Europe, North America and Australia [7]. In addition to RAPD, other molecular markers have been used to study the genetic diversity of plant genotypes based on DNA polymorphism to differentiate plant species and populations and identify distinct genotypes and superior hybrids from a cross population [8-13]. In alfalfa, SSR markers and phenotypic traits revealed similar genetic diversity of 12 feral alfalfa populations originating from southern Manitoba in Canada and ten alfalfa cultivars but both were different from a Medicago falcata germplasm [14]. Genetic diversity among 18 non-dormant alfalfa, accessions including ten local ecotypes and eight introduced accessions were studied at the morpho-agronomic and molecular levels using sequence-related amplified polymorphism (SRAP) markers (loci), which are relatively widely distributed across the plant genome [15]. The SRAP data differentiated widely distributed lucerne populations, across different environments and identified good genetic resources for breeding purposes [16]. SRAP was also effectively used to estimate genetic diversity among Tunisian alfalfa genotypes and provided identification and rational use of local and foreign alfalfa populations for breeding programs focusing on the development of new, high-yielding cultivars that are more adapted to the drought conditions in North Africa [17].

Retrotransposons (RTNs) are the most common class of transposable elements in eukaryotes and occur in high copy number in plant genomes [18]. Inter-retrotransposon amplified polymorphism (IRAP) and retrotransposon-microsatellite amplified polymorphism (REMAP) were developed as new retrotransposon-based DNA fingerprinting techniques that produce dominant, multiplex marker systems that examine variation in retrotransposon insertion sites. The IRAPs are good molecular markers due to the high number of copies of retrotransposons in plant genomes and to the fact that they can create new copies [19]. RTNs markers derived from IRAP and REMAP were compared with ISSR, and SSR markers for evaluation of genetic diversity of alfalfa [20]. They concluded that the RTNs markers have the advantage of being easy to assess, their low cost as well as being more informative and polymorphic. The RTNs markers have been used for investigating the genetic diversity in several plants. For example, genomic stability in populations of the young allopolyploid species Spartina anglica [21], and the Iranian bread wheat cultivars and breeding lines of wheat [22] and the assessment of genetic diversity and relationships among Triticum species and populations from Iran $[23,24]$. The genetic diversity of Bletilla striata was also assessed by IRAP and the start codon targeted (SCOT) markers [25].

DNA barcoding for plant species identification, based on the use of a standard gene fragment, for plant species identification, was introduced by Hebert et al. [26] and was developed rapidly in the first decade of the 21st century [27]. The plant working group proposed the chloroplast genes $r b c \mathrm{~L}$ and $m a t \mathrm{~K}$ as the core barcodes of plant species, as well as the intergenic sequence trn $\mathrm{H}-p s b \mathrm{~A}$ and the nuclear internal transcript spacer sequence (ITS) as supplement barcodes [27]. DNA barcoding may also provide 
indications of genetic divergence present in populations and assists in comparative investigations of population diversity [28]. In recent years, DNA barcoding have become a useful tool for investigating and monitoring biodiversity and in phylogeny reconstruction and plant evolution studies [29] although alignment of the $t r n \mathrm{H}-p s b \mathrm{~A}$ spacer region needs careful attention [30]. Combined universal chloroplast and nuclear DNA sequence targets was applied to barcode the major Mediterranean leguminous crops [31]. The combination of universal chloroplast and nuclear DNA sequence targets was applied to barcode the major Mediterranean leguminous crops [32].

Genetic diversity of $M$. sativa has been frequently characterized using morphological traits [33], sometimes in combination with molecular markers [16]. Warburton and Smith (1993) suggested that there were at least six regional germplasm groups of non-dormant alfalfa among the North African, Arabian, and Indian germplasm [34]. Canonical discrimination functions showed that $75 \%$ of total morphological variability among accessions of 18 non-dormant alfalfa was strongly influenced by leaflet shape, stipule shape, and the peduncle, that is, the petiole length ratio [16]. The development of improved alfalfa cultivars may have altered some of the traits of ancestral populations that were associated with inherent yield and could have contributed to the relatively narrow genetic base that is now available for breeding [35-37].

The objective of the current study is to use the IRAP markers to differentiate 15 selected cultivars of M. sativa. In addition, analysis of fifteen morpho-agronomic traits and DNA barcoding, using the two chloroplast genes $m a t \mathrm{~K}$ and $t r n \mathrm{H}$ are used to assess the genetic relatedness and ancestry of the selected alfalfa cultivars.

\section{Material and Methods}

\subsection{Plant Material}

Fifteen M. sativa cultivars were kindly assessed by ICARDA, research program of crop genetics, currently at the Agricultural Genetic Engineering Research Institute (AGERI), Agricultural Research Center (ARC), Giza, Egypt. The samples include two cultivars from Egypt, three from Australia and ten from the United States of America as listed in Table 1.

Table 1. Origin, codes, and names of the alfalfa cultivars as recorded by ICARDA and the Genebank deposited accession numbers for matK and $\operatorname{trn} \mathrm{H}$ genes for eight cultivars of Medicago sativa.

\begin{tabular}{|c|c|c|c|c|c|}
\hline No. & Origin & Code ${ }^{\#}$ & Cultivar Name & $\begin{array}{c}\text { matK Genebank } \\
\text { Accession }\end{array}$ & $\begin{array}{c}\text { trnH Genebank } \\
\text { Accession }\end{array}$ \\
\hline 1 & \multirow{2}{*}{ Egypt (EGY) } & EGY1 & Ismailia1 * ARC & MN509171 & MN509787 \\
\hline 2 & & EGY1 & Nubaria1 * ARC & MN509788 & MN610248 \\
\hline 3 & \multirow{3}{*}{ Australia (AUS) } & AUS2 & Siri-Nafa * Australia & MN509173 & MN610246 \\
\hline 4 & & AUS3 & Siriver Australia & NA & NA \\
\hline 5 & & AUS4 & SuperFast Saudi Arabia & NA & NA \\
\hline 6 & \multirow{10}{*}{$\begin{array}{l}\text { United States of } \\
\text { America (USA) }\end{array}$} & USA1 & Super-supreme ${ }^{*}$ California & MN509175 & MN509790 \\
\hline 7 & & USA2 & Nafa Extra USA & NA & NA \\
\hline 8 & & USA3 & Grasis II California & NA & NA \\
\hline 9 & & USA4 & Cuf101* California & MN509177 & MN610247 \\
\hline 10 & & USA5 & Supreme forager California & NA & NA \\
\hline 11 & & USA6 & SW9720 California & NA & NA \\
\hline 12 & & $\mathrm{USA}^{\times}$ & SW9628 *-California & MN610249 & MN509792 \\
\hline 13 & & $\mathrm{USA}^{\times}{ }^{\times}$ & Magna901* Diary Land & MN509174 & MN509789 \\
\hline 14 & & USA9 $^{\times}$ & Perfect * California & MN509172 & MN610245 \\
\hline 15 & & USA10 & Super10 California & NA & NA \\
\hline
\end{tabular}

\footnotetext{
\# Three digit codes used in this study are according to official ISO country codes that were listed on http: //www.nationsonline.org/oneworld/country_code_list.htm and http://www.worldatlas.com/aatlas/ctycodes.htm. * Refers to the cultivars used for DNA barcoding. ${ }^{\times}$Refer to cultivars not used for inter-retrotransposon-amplified polymorphism (IRAP) markers.
} 


\subsection{Extraction, Purification, and Quantification of Genomic DNA of M. sativa Cultivars}

High molecular weight genomic DNA was isolated from 50-100 mg ground and freeze-dried seed meals of M. sativa cultivars based on the procedures of Murray and Thompson (1980) using DNeasy Plant Mini Kit (QIAGEN, Hilden, Germany). The quantity and purity of extracted DNA were assessed spectrophotometrically using the ND-1000 system (Nano-Drop Technologies, Thermo Fisher Scientific Inc., Waltham, MA, USA). DNA manipulation and analysis procedures in terms of quantification and purity analysis were performed according to the Molecular Cloning Laboratory Manual [38].

\subsection{IRAP Primer and IRAP Marker PCR Amplification}

Eleven IRAP primers of those designed by Kalendar and Schulman (2014) were used (Table 2). The primers were synthesized by HVD Vertriebs-Ges. m.b.H. (Vienna, Austria) in 10 nmol stock concentration, delivered in a lyophilized form, rehydrated in sterile water to reach the $100 \mu \mathrm{M}$ final concentration, and finally stored at $-20^{\circ} \mathrm{C}$ until used. IRAP-PCR amplification was carried out in $25 \mu \mathrm{L}$ reaction volume containing $1 \times \mathrm{PCR}$ master mix buffer supplemented by $1.5 \mathrm{mM} \mathrm{MgCl}_{2}, 25 \mu \mathrm{M}$ primer, and $75 \mathrm{ng}$ genomic DNA. The amplification process was performed in a Perkin-Elmer/GeneAmp ${ }^{\circledR}$ PCR System 9700 (PE Applied Biosystems, Waltham, MA, USA) programmed to initial denaturation cycle for $3 \mathrm{~min}$ at $94^{\circ} \mathrm{C}$ followed by 35 cycles, with each cycle consisting of a denaturation at $94{ }^{\circ} \mathrm{C}$ for $1 \mathrm{~min}$, annealing at $55^{\circ} \mathrm{C}$ for $1 \mathrm{~min}$, and elongation at $72{ }^{\circ} \mathrm{C}$ for $1.5 \mathrm{~min}$. The primer extension segment was extended to $7 \mathrm{~min}$ at $72{ }^{\circ} \mathrm{C}$ in the final cycle. Visualization and documentation of the PCR products were executed by using Bio-Rad ChemiDoc ${ }^{\mathrm{TM}}$ MP gel documentation and image system (Cat. no. 1708280).

Table 2. IRAP primer names, sequences, total number of amplicons (TNAs), monomorphic amplicons (MAs), polymorphic amplicons (PAs), percentage of polymorphism $(\% \mathrm{P})$, polymorphism information content (PIC), resolving power (RP), effective multiplex ratio (EMR), and marker index (MI) as revealed by IRAP profiles in 11 M. sativa L. cultivars.

\begin{tabular}{|c|c|c|c|c|c|c|c|c|c|c|}
\hline No. & $\begin{array}{l}\text { Primer } \\
\text { Name }\end{array}$ & Sequence $\left(5^{\prime}-3^{\prime}\right)$ & TNAs & MAs & PAs & $\% \mathbf{P}$ & PIC & $\mathbf{R P}$ & EMR & MI \\
\hline 1 & IRAP4352 & ACCCGGAAGGGCGGTTCATGCAA & 9 & 1 & 8 & 89 & 0.78 & 6.5 & 7.11 & 5.57 \\
\hline 2 & IRAP 4334 & CCATGGCGAGCAGATGTGCT & 11 & 0 & 11 & 100 & $\underline{0.88}$ & 7 & $\underline{11}$ & 9.67 \\
\hline 3 & IRAP 4348 & TTAGATGAAACCAACGATCCCAAGGCT & 13 & 3 & 10 & 77 & $\overline{0.52}$ & 16 & 7.69 & 4.02 \\
\hline 4 & IRAP 4370 & ATGCCGTATTCTCAGCATCC & 14 & 0 & 14 & 100 & 0.81 & 10.2 & 14 & 11.41 \\
\hline 5 & IRAP 4377 & CGTACCCTTTTAAGGGATCAAAACC & 9 & 2 & 7 & $\overline{78}$ & 0.53 & 10.8 & 5.44 & 2.91 \\
\hline 6 & IRAP 4351 & CAGGCAAGAATGAGCGTCTC & 3 & 2 & 1 & $\underline{33}$ & 0.1 & 5.7 & 0.33 & 0.03 \\
\hline 7 & IRAP 4340 & ATGGTTGTCGAAACTCCAGC & 21 & 0 & 21 & 100 & 0.83 & 14.2 & 21 & 17.36 \\
\hline 8 & IRAP 4342 & GATTGCAAAGCCTATTTCGCTG & 4 & 0 & $\overline{4}$ & 100 & 0.59 & 4.3 & 4 & 2.34 \\
\hline 9 & IRAP 4375 & ATCGCTCCGGGTGCCTAACAC & 4 & 2 & 2 & $\overline{50}$ & 0.28 & 6.7 & 1 & 0.28 \\
\hline 10 & IRAP 3471 & ATCGCTCCGGGTGCCTAACAC & 5 & 0 & 5 & 100 & 0.61 & 5.5 & 5 & 3.06 \\
\hline \multirow[t]{3}{*}{11} & IRAP 4357 & TGACATTTGTGGCACTTTCTGGCGT & 4 & 2 & 2 & $\overline{50}$ & 0.28 & 6.7 & 1 & 0.28 \\
\hline & & Total & 97 & 12 & 85 & NA & NA & NA & NA & NA \\
\hline & & Mean & & & 7.72 & 79.73 & 0.56 & 8.50 & 7.05 & 5.17 \\
\hline
\end{tabular}

Underlined values denote the minimum and maximum value of each estimated parameter.

\subsection{DNA Barcoding of mat K and trn H Plastid Genes}

For the matK and trnH barcoding, the forward and reverse primers sequences given in Table 3 have been used. The PCR amplification of the two gens was performed at initial denaturation of $5 \mathrm{~min}$ at $94{ }^{\circ} \mathrm{C}$ followed by 40 cycles, each consists denaturation at $94{ }^{\circ} \mathrm{C}$ for $30 \mathrm{~s}$, annealing step at $45^{\circ} \mathrm{C}$ for $30 \mathrm{~s}$, and elongation at $72{ }^{\circ} \mathrm{C}$ for $30 \mathrm{~s}$. The primer extension segment was extended for $7 \mathrm{~min}$ at $72{ }^{\circ} \mathrm{C}$ in the final cycle. PCR specific products were subsequently electrophoresed on $1.5 \% w / v$ agarose, stained with EtBr (final concentration $100 \mu \mathrm{M} / \mathrm{L}$, Sigma-Aldrich ${ }^{\circledR}$, St. Louis, MO, USA) in $1 \times$ TBE buffer and visualized as described for the IRAP PCR products. Fractionated PCR amplicons of matK and trnH amplified fragments were recovered from agarose gel using QIAquik ${ }^{\circledR}$ PCR PURIFICATION KIT (Qiagen Inc., Venlo, The Netherlands, Cat. no. 28106) according to the manufacturer's instructions. Selected and purified amplicons were then cloned into pGEM cloning vector prior to sequencing. 
Table 3. Primer codes and sequences for barcoding the mat $\mathrm{K}$ and $t r n \mathrm{H}$ genes.

\begin{tabular}{|c|c|c|c|}
\hline Primer Code & Sequence & Product Size & Reference \\
\hline $\operatorname{trn} \mathrm{H}-\mathrm{F}$ & 5'-GTTATGCATGAACGTAATGCTC-3' & \multirow{2}{*}{$700 \mathrm{bp}$} & [31] \\
\hline $\operatorname{trnH}-\mathrm{R}$ & 5'-CGCGCATGGTGGATTCACAATCC-3' & & [32] \\
\hline matK-472F & 5'-CCCRTYCATCTGGAAATCTTGGTTC-3' & \multirow{2}{*}{$700 \mathrm{bp}$} & \multirow{2}{*}{ [33] } \\
\hline matK-1248R & 5'-GCTRTRATAATGAGAAAGATTTCTGC-3' & & \\
\hline
\end{tabular}

The DNA sequence was determined by automated DNA sequencing reactions performed using ABI PRISM Big Dye Terminator Cycle Sequencing Ready Reaction Kit (PE Applied Biosystems, Waltham, MA, USA) in conjunction with ABI PRISM (3100 Genetic Analyzer, Macrogene DNA sequencing services, Seoul, Rep. of Korea). DNA sequencing was executed using the Gene Amp 2400 Thermal Cycler. The reaction was performed in $20 \mu \mathrm{L}$ including $7 \mu \mathrm{L}$ of terminator ready reaction mix, $0.5 \mu \mathrm{g}$ of plasmid DNA, and 3.2 pmol M13 universal forward primer. The sequence cycling was programmed to $95{ }^{\circ} \mathrm{C}$ for $10 \mathrm{~s}, 55^{\circ} \mathrm{C}$ for $5 \mathrm{~s}$, and $65^{\circ} \mathrm{C}$ for $4 \mathrm{~min}$ for 30 cycles with thermal ramping according to manufacturer's recommendations. The sequence of nucleotides was detected automatically by the electrophoresis of the sequencing reaction product on 3100 Genetic Analyzer. The result was provided as fluorimetric scans and revealed nucleotide sequence was assembled using Gblocks software version $0.91 \mathrm{~b}[39,40]$.

The relationship among the eight M. sativa cultivars, used for phylogenetic relatedness using the DNA barcoding of matK and trnH plastid genes, were also investigated using variation in 15 morpho-agronomic traits as described by Moawed [41]. A list of these traits and their states and description in the eight cultivars are given in Table 5. These traits were regarded as two state characters and scored as a binary matrix and analyzed by the Principle Coordinates Analysis (PCA) to calculate the relatedness of the examined cultivars and determine the impact of the morpho-agronomic traits on the plotting of cultivars in a PCA biplot.

\subsection{Data Analysis}

The clear distinct reproducible bands generated as IRAP markers were scored as (1) for presence or (0) for absence. The capacity of IRAP primers to discriminate between examined genotypes were analyzed by means of calculating the polymorphic information content (PIC), Resolving power (Rp), Marker Index (MI), and effective multiplex ratio (EMR) values. PIC value for each primer, representing the reflection of the degree of detecting polymorphism, was calculated according to Ghislain et al. [42]. $\mathrm{Rp}$ was calculated following the formula of Gilbert et al. [43]. $\mathrm{Rp}=\Sigma \mathrm{IB}$, where IB represents band informativeness which was calculated using: $l b=1-(2 \times|0.5-p|)$, where $P$ is the frequency of accessions that harbor bands. EMR and MI values were estimated according to Powell et al. [44]. The IRAP markers matrix were used to calculate the coefficient of genetic similarity matrix and construct a distance tree displaying relationships among cultivars using the unweighted pair group method with arithmetic mean (UPGMA) using PAST, ver. 4.02 software [45]. In addition, principal component analysis (PCA) scatter diagram was constructed based on Dice coefficient genetic similarity matrix by using PAST, ver. 4.02 software [45]. The multivariate analysis was performed through constructing a Heatmap matrix using the module of R software.

Computational analysis of matK and trnH DNA barcoding sequences was carried out. Analysis and assembling of matK/trnH gene sequences for every cultivar was performed via BioEdit software version 7.2.5. Latter sequences were then compared using BLAST function (www.ncbi.nlm.nih.gov/ bastn) with all accessible sequences in database. matK/trnH gene sequences were submitted to GenBank (BankIt). Alignment of multiple nucleotide sequences were performed by online ClustalW2 (https://www.ebi.ac.uk/Tools/msa/clustalw2/) and double checked by using MEGAX. Gaps positions were checked and assessed in Gblocks Version 0.91b [39,40]. Phylogenetic analysis was performed in MEGAX software using UPGMA algorithm. Confidence of the clustering was executed in SEQBOOT 
and followed then by running the data set for 500 replication times in each of the previous programs. The bootstrap values were written on the nodes of generated phylogenetic trees. In addition, PCA biplot based on the morpho-agronomic data matrix was constructed by the multivariate analysis of PAST ver. 4.02 software [45].

\section{Results}

\subsection{Molecular Characterization and Genetic Relationships as Revealed by IRAP Markers}

The IRAP fingerprinting profiles generated by the eleven primers targeting inter-retrotransposons in 12 alfalfa cultivars are shown in Figure 1. The polymorphism produced by the same 11 IRAP primers is summarized in Table 2. These primers generated a total of 97 amplicons; 85 of these were polymorphic (87.6\%). The number of total bands ranged from 3 for primer IRAP-4351 to 21 for primer IRAP-4340; the number of polymorphic bands also varied greatly between 1 and 21 in the cases of IRAP-4351 and IRAP-4340 primers, respectively. Hereby, the average number of polymorphic amplicons was 7.7 per primer. The PIC values varied among the IRAP primers; it ranged from the lowest value of 0.1 for primer IRAP-4351 to the highest value of 0.88 for primer IRAP-4334. Notably, some IRAP primers revealed a pronounced discrimination of $100 \%$ polymorphism, including IRAP-4334 and IRAP-4340. IRAP-4334 recorded the highest PIC and EMR values (0.88 and 11, respectively), whereas IRAP-4340 scored the highest RP and MI values (14.2 and 17.36, respectively). On the other hand, primer IRAP-4351 recorded the lowest PIC value (0.1) with the lowest (33\%) polymorphism percentage.

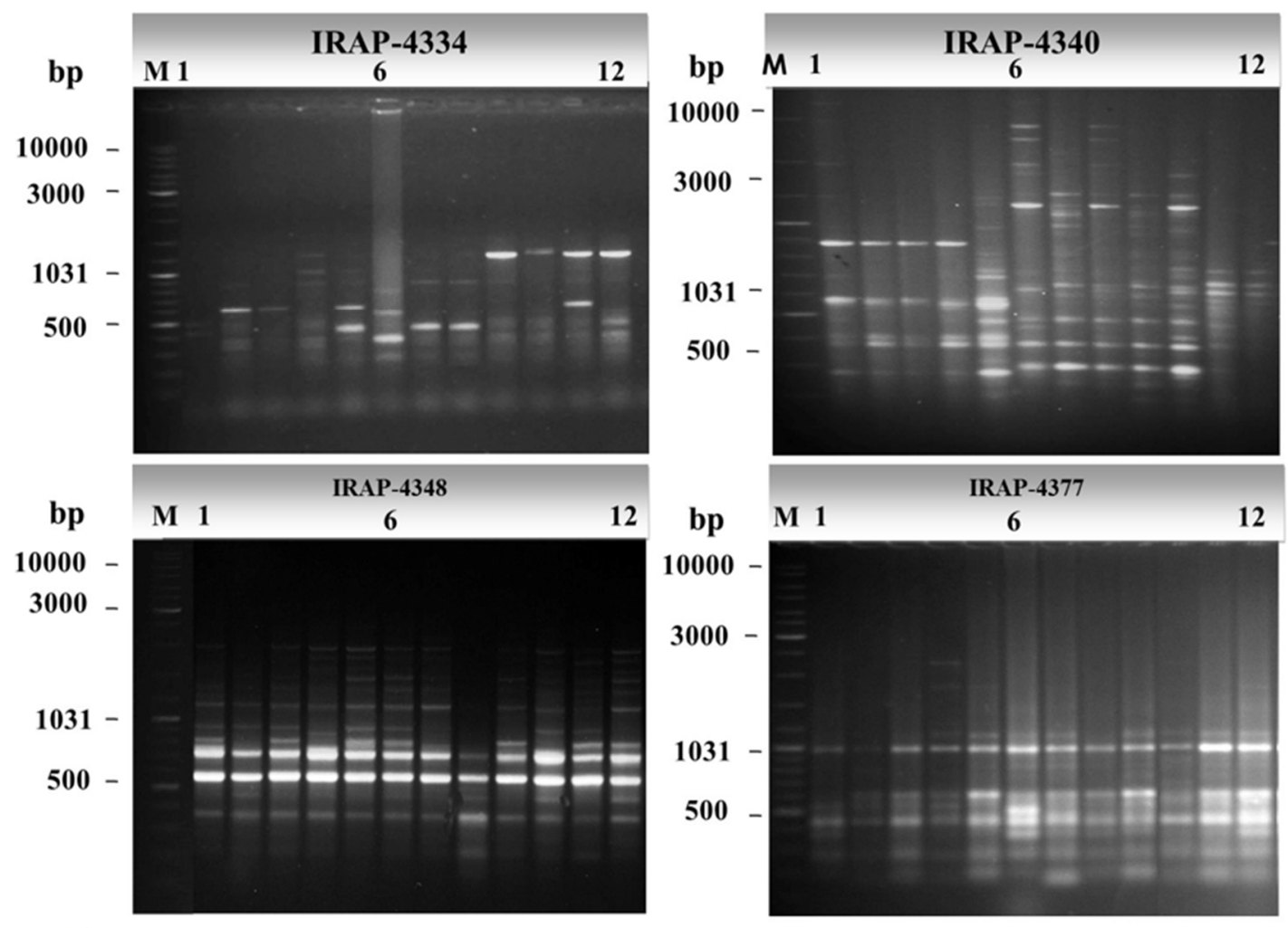

Figure 1. Agarose gel electrophoresis of PCR amplicons of some representative IRAP primers showing polymorphism of IRAP markers. DNA size marker Gene-Ruler $1 \mathrm{~Kb}$ plus DNA ladder (lane M) was used as molecular size standards in bps. Numbers from 1 to 12 refer to the sampling numbers of studied cultivars. 
The IRAP marker data for 12 alfalfa cultivars were used to produce a genetic distance tree based on Dice's genetic similarity matrix (Figure 2). In this tree, the two Egyptian cultivars, EGY2-Nubaria1 and EGY1- Ismailia1, were clearly separated from the other cultivars, while the USA6-SW9720 and the AUS4-SuperFast cultivars were distinguished as two branches. The other two Australian cultivars were then differentiated from the five USA cultivars; AUS2-Siri Nafa and AUS3-Siriver clustered together and USA10-Super10 was distinct as one branch. USA1-Super-supreme and USA2-Nafa Extra clustered together and the other three cultivars clustered. USA1-Super-supreme and USA2-Nafa Extra clustered together and the other three formed another cluster. The similarity matrices among the $12 \mathrm{M}$. sativa cultivars as computed using Dice's coefficient based on IRAP molecular marker polymorphism are given in Supplementary Table S1.

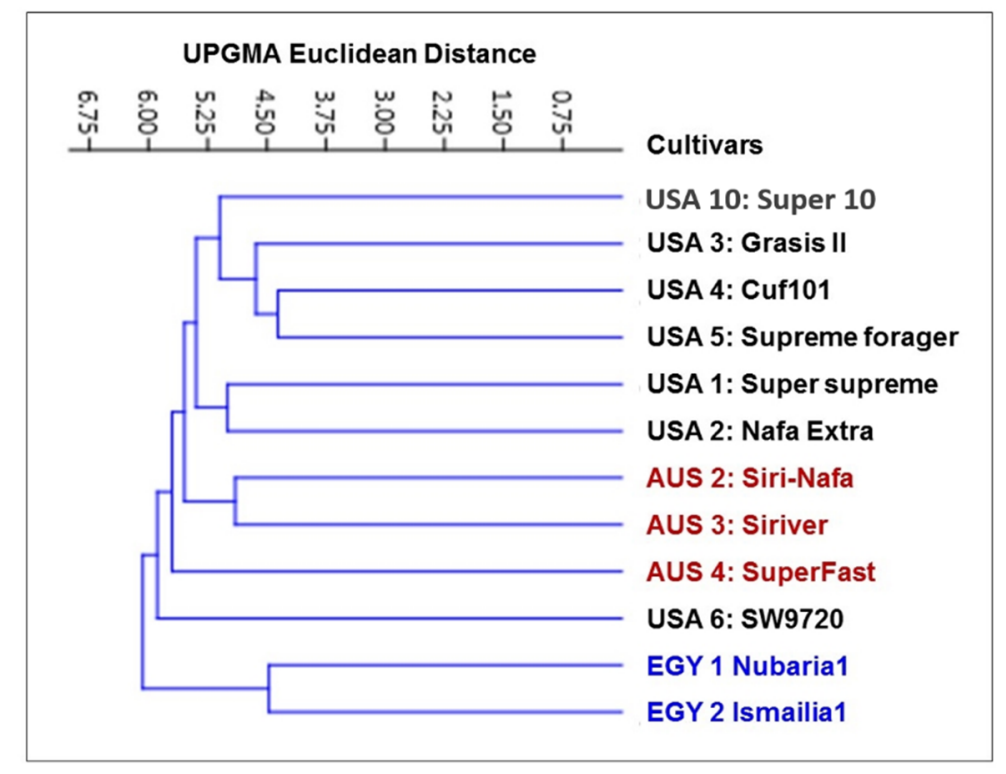

Figure 2. Cluster tree illustrating the relationship of $12 \mathrm{M}$. sativa cultivars based on the analysis of IRAP marker polymorphism, constructed using the Euclidean similarity matrices computed as Dice coefficients and using the unweighted pair group method with arithmetic mean (UPGMA) algorithm in the PAST software.

The PCA analysis reflecting the strength of the IRAP markers to classify the examined cultivars in a PCA scatter plot by plotting of PC1 and PC2, clearly discriminated the two Egyptian cultivars (Figure 3) and revealed the characteristic grouping of the EGY1-Ismailia1 and EGY2-Nubaria1 cultivars. In the same context, the Australian cultivars AUS2-Siri-Nafa, AUS3-Siriver and AUS4-SuperFast were grouped together, but USA10-Super10 was grouped with USA3-Grasis II. On the other hand, the rest of the American cultivars, USA1-Super-supreme, USA4-Cuf101, USA5-Supreme forager and USA6-SW9720, were scattered with some distance to each other.

Multivariate heatmap analysis was also used to construct a heatmap using the heatmap module of R software. The twelve cultivars clustered, as shown by the columns, into five clusters of two or three cultivars (Figure 4). The first cluster grouped the Egyptian cultivars together adjacent to USA10-Super10. The cultivars AUS4-SuperFast, USA2-Nafa Extra and the cultivars AUS2-Siri Nafa and AUS3-Siriver are differentiated as two neighboring pairs of cultivars. The other five American cultivars appeared as two neighboring clusters: one of USA1-Super-supreme and USA3-Grasis II and the other of USA4-Cuf101, USA5-Supreme forager and USA6-SW9720. 


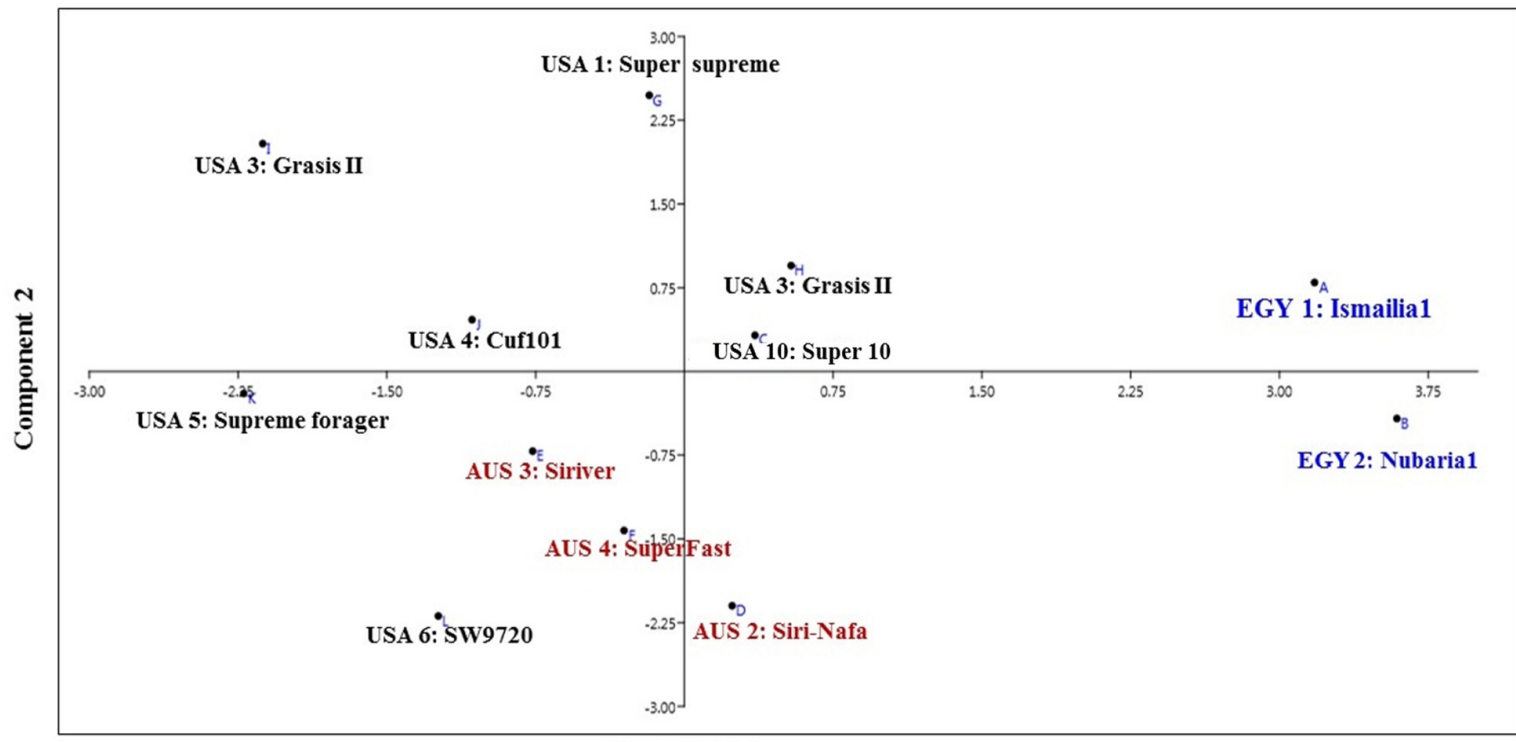

Component 1

Figure 3. Principal component analysis (PCA) scatter diagram illustrating the genetic diversity expressed by the grouping of $12 \mathrm{M}$. sativa cultivars based on the analysis of IRAP marker polymorphism and by blotting the first two principal components using PAST software.

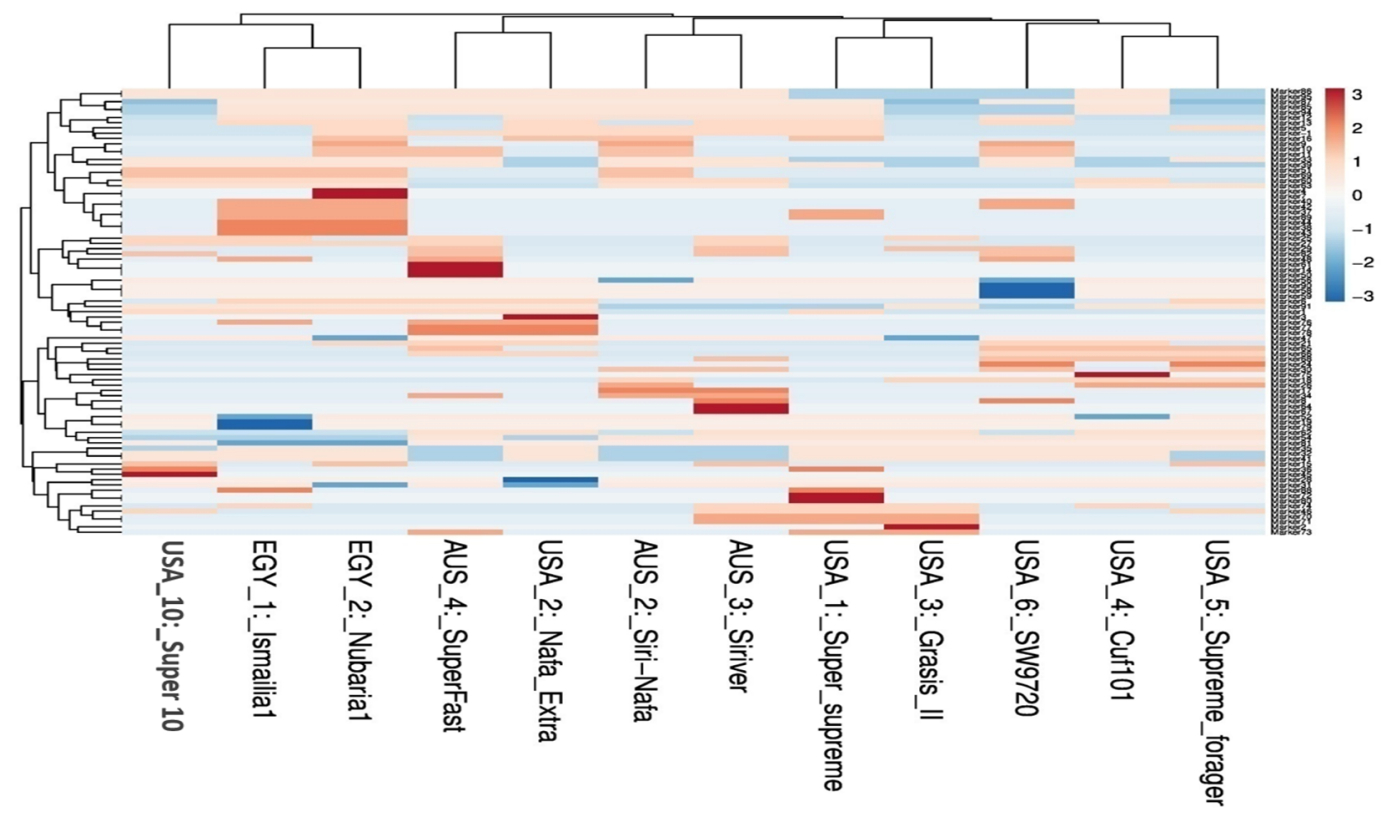

Figure 4. Multivariate heatmap illustrating the genetic diversity of $12 \mathrm{M}$. sativa cultivars based on the IRAP markers constructed using the module of heatmap of $\mathrm{R}$ software.

\subsection{DNA Barcoding Loci of matK and trnH Sequencing}

Two DNA barcoding loci mat $\mathrm{K}$ and $t r n \mathrm{H}$ from the chloroplast genome were compared for their amplification, sequencing, and successful use in measuring the genetic diversity and phylogeny among eight alfalfa cultivars marked by an asterisk $\left(^{*}\right)$ in Table 1 . These include the two Egyptian cultivars, AUS2-Siri Nafa, and five USA cultivars (USA1-Super-supreme, USA4-Cuf101, USA7-SW9623, USA8-Magna901 and USA9-Perfect). PCR amplification products of mat $\mathrm{K}$ and $t r n \mathrm{H}$ regions showed $100 \%$ amplification success across all eight cultivars and agarose electrophoresis results demonstrated 
sharp DNA bands with no byproducts, indicating high specificity of PCR reactions (Supplementary Figure S1).

The produced DNA fragments recorded a size of a $700 \mathrm{bp}$ for both mat $\mathrm{K}$ and $\operatorname{trn} \mathrm{H}$. To ensure that the mat $\mathrm{K}$ and $\operatorname{trn} \mathrm{H}$ sequences, generated in the present study, were of $M$. sativa species, a BLAST function detected that all the sequences strongly matched Medicago sativa and Medicago truncatula $m a t \mathrm{~K}$ and $t r n \mathrm{H}$ sequences. Pairwise distances were obtained and assessed from the sequences of the conserved $m a t \mathrm{~K}$ and $t r n \mathrm{H}$ sequence. Additional information on the genetic variation estimates of DNA barcoding regions of mat $\mathrm{K}$ and $\operatorname{trn} \mathrm{H}$ loci in eight cultivars of $M$. sativa is given in Table 4, particularly the aligned length, undetermined characters, missing percent, variable sites and the proportion of variable sites, and parsimony informative sites. The evaluation of sequence estimates of DNA barcoding locus of matK locus is given in Supplementary Tables S2 and S3.

Table 4. Genetic variation estimates of DNA barcoding of the mat $\mathrm{K}$ and $t r n \mathrm{H}$ genes in the eight cultivars of M. sativa.

\begin{tabular}{cccccccccc}
\hline $\begin{array}{c}\text { Gene } \\
\text { Name }\end{array}$ & $\begin{array}{c}\text { Aligned } \\
\text { Length }\end{array}$ & $\begin{array}{c}\text { Undetermined } \\
\text { Characters }\end{array}$ & $\begin{array}{c}\text { Missing } \\
\text { Percent }\end{array}$ & $\begin{array}{c}\text { Variable } \\
\text { Sites }\end{array}$ & $\begin{array}{c}\text { Proportion } \\
\text { Variable } \\
\text { Sites }\end{array}$ & $\begin{array}{c}\text { Parsimony } \\
\text { Informative } \\
\text { Sites }\end{array}$ & $\begin{array}{c}\text { Proportion } \\
\text { Parsimony } \\
\text { Informative }\end{array}$ & AT\% & GC\% \\
\hline matk & 911 & 863 & 13.53 & 327 & 0.359 & 194 & 0.213 & 0.66 & 0.34 \\
\hline trnH. & 755 & 521 & 8.63 & 31 & 0.041 & 4 & 0.005 & 0.64 & 0.36 \\
\hline
\end{tabular}

A phylogenetic tree generated based on matK sequence variation using the UPGMA algorithm clearly discriminated between the eight alfalfa studied sequences (Figure 5). To manifest the accuracy and efficacy of the generated tree, five NCBI-extracted matK sequences belonging to four M. sativa (NC_042841.1) and its subspecies X-varia (HM159582.1), glomerate (MK46595494) and caerulea (HM159580.1) as well as M. truncatula (NC_003119.1) were used as outgroups. The tree has two major clades: One includes the Egyptian cultivars EGY1-Ismailia1 and EGY2-Nubaria1 along with M. sativa NCBI-extracted matK and its subspecies members and USA9-Perfect. The second includes the five USA cultivars, USA4-Cuf101, USA7-SW9623, USA8-Magna901 and USA1-Super-supreme grouped with $M$. truncatula, which is used as an outgroup member. The bootstrap values are very high $(98-100 \%)$, confirming the validity of the tree branching. A PCA scatter plot based on the of matK barcoding (Supplementary Figure S2) confirmed the classification of the examined cultivars as indicated in the phylogenetic tree generated by the mat $\mathrm{K}$ locus sequence. This figure revealed the characteristic grouping of EGY1-Ismailia1 and EGY2-Nubaria1 cultivars and the distinction of AUS2-Siri Nafa and USA4-Cuf101. A multivariate heatmap analysis of the matK sequence generated using the heatmap module of R software (Supplementary Figure S3) also confirmed the distinction of the Egyptian cultivars EGY1-Ismailia1 and EGY2-Nubaria1 and AUS2-Siri Nafa from the USA cultivars.

On the other hand, similarity matrix revealed a variation between $\operatorname{tr} n \mathrm{H}$-generated sequences among the $M$. sativa cultivars. A phylogenetic tree was constructed based on this variation in eight alfalfa cultivars using $\operatorname{trn} \mathrm{H}$ of $M$. sativa (NC-042841.1; M. falcata (NC-032066.1) and M. truncatula (NC-003119.1) (Figure 6) as three outgroups.

The tree clearly isolated the three outgroups from the major clade of the eight alfalfa cultivars used for $\operatorname{trn} \mathrm{H}$ barcoding. In this clade, AUS2-Siri Nafa and the two Egyptian cultivars sequences EGY1-Ismailia1 and EGY2-Nubaria1 were clearly isolated from the five American cultivars. A phylogenetic heatmap analysis of the $\operatorname{trn} \mathrm{H}$ sequence generated using the heatmap module of $\mathrm{R}$ software (Supplementary Figure S4) also confirmed the distinction of the Egyptian cultivars EGY1-Ismailia1 and EGY2-Nubaria1 and AUS2-Siri Nafa from Australia. 


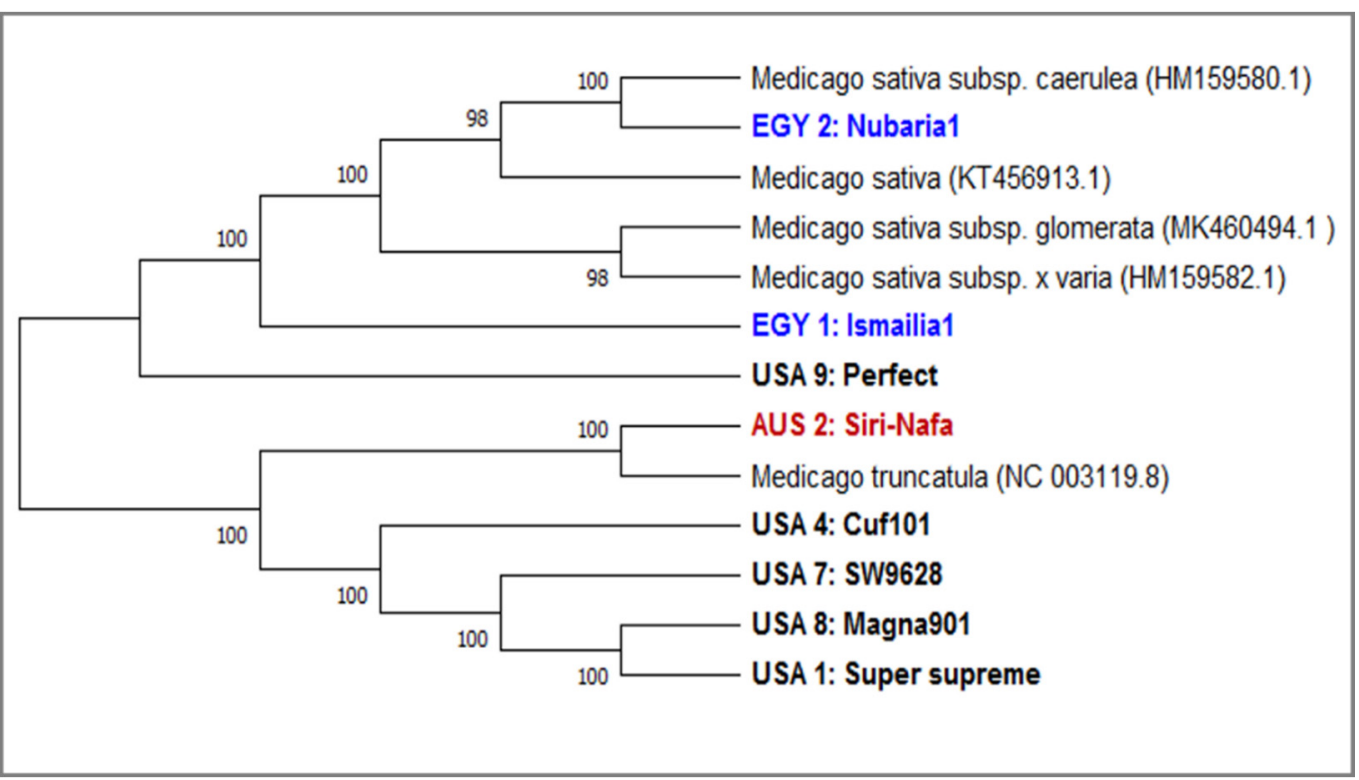

Figure 5. A consensus phylogenetic tree constructed based on the matK DNA barcoding region for nine $M$. sativa cultivars using the MEGAX software. An additional three sequences of $M$. sativa L. matK sequences were used as outgroups. The tree has a branch length of 2.8667 and the bootstrap values shown next to the branches indicate the bootstrap value supporting this node. The evolutionary distances were computed using the Jukes-Cantor method based on base substitutions per site. The ambiguous pairwise deletion option was used.

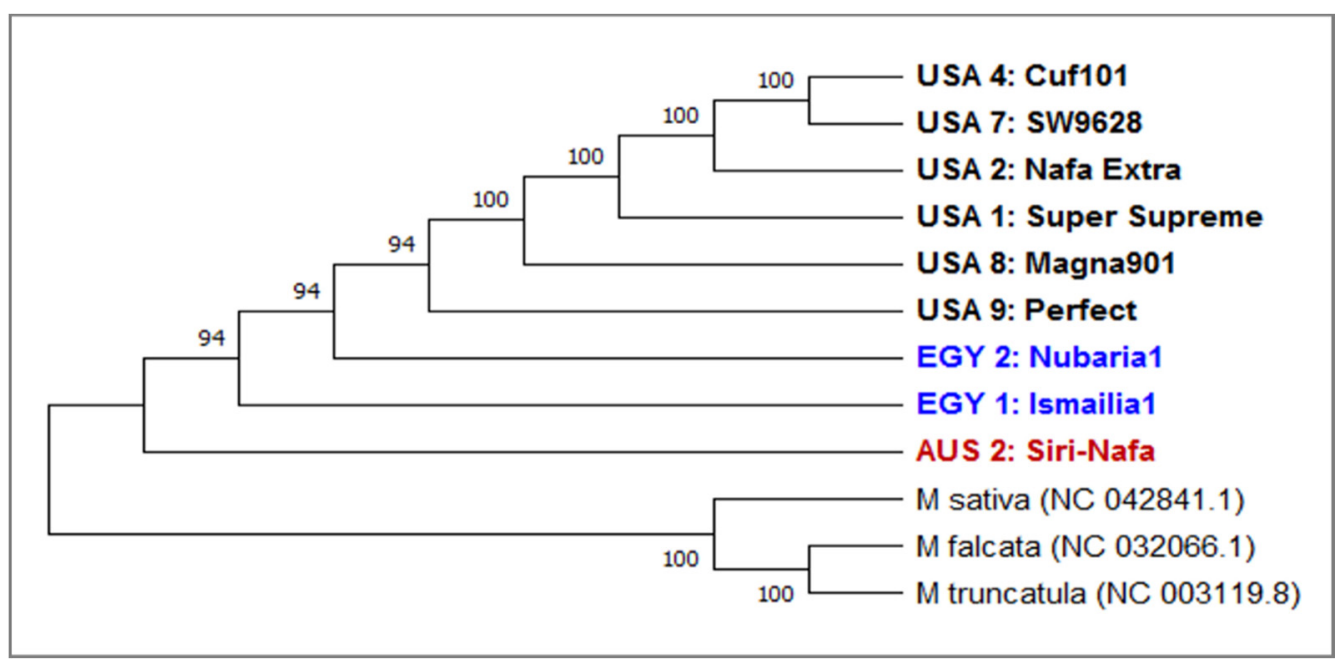

Figure 6. A consensus phylogenetic tree constructed based on trnH DNA barcoding regions for nine M. sativa cultivars using the MEGAX software. The evolutionary history was inferred using the UPGMA method. The optimal tree has a branch length of 0.905444 . The bootstrap values are shown next to the branches. The evolutionary distances were computed using the Jukes-Cantor method and are in the units of the number of base substitutions per site. This analysis involved 12 nucleotide sequences. All ambiguous positions were removed for each sequence pair (pairwise deletion option). There was a total of 60 positions in the final dataset.

In addition to the genetic diversity among the alfalfa cultivars, the variation in 15 morpho-agronomic traits (Table 5), applicable only to eight $M$. sativa cultivars, was dissected. A distance cluster tree, illustrating the classification of M. sativa cultivars, was constructed based on the Euclidean distance of variation in the studied morpho-agronomic traits using the UPGMA algorithm (Figure 7). 
Table 5. List of 16 morpho-agronomic traits and their state in the eight alfalfa cultivars used for phylogeny of these cultivars using matK and trn $\mathrm{H}$ gene sequences.

\begin{tabular}{|c|c|c|c|c|c|c|c|c|}
\hline Characters and Their Abbreviations & $\begin{array}{c}\text { EGY1: } \\
\text { Ismailia1 }\end{array}$ & $\begin{array}{c}\text { EGY2: } \\
\text { Nubaria1 }\end{array}$ & $\begin{array}{c}\text { AUS2: } \\
\text { Siri-Nafa }\end{array}$ & $\begin{array}{c}\text { USA1: } \\
\text { Super Supreme }\end{array}$ & $\begin{array}{l}\text { USA4: } \\
\text { Cuf101 }\end{array}$ & $\begin{array}{c}\text { USA7: } \\
\text { SW9628 }\end{array}$ & $\begin{array}{c}\text { USA 8: } \\
\text { Magna } 901\end{array}$ & $\begin{array}{l}\text { USA9: } \\
\text { Perfect }\end{array}$ \\
\hline Resistance to pests: RP & sensitive & sensitive & resistant & sensitive & sensitive & sensitive & sensitive & sensitive \\
\hline Plant height $(\mathrm{cm}): \mathrm{PH}$ & $\geq 70$ & $\geq 70$ & $<70$ & $\geq 70$ & $\geq 70$ & $<70$ & $<70$ & $<70$ \\
\hline Stem number: SN & $<4$ & $<4$ & $<4$ & $\geq 4$ & $\geq 4$ & $<4$ & $<4$ & $<4$ \\
\hline Petiole length (mm): PtL & $<20$ & $<20$ & $<20$ & $\geq 20$ & $<20$ & $<20$ & $<20$ & $<20$ \\
\hline Petiole hairiness: $\mathrm{PtH}$ & glabrous & hairy & hairy & glabrous & glabrous & glabrous & hairy & glabrous \\
\hline Terminal leaflet length (mm): TlL & $<20$ & $\geq 4$ & $<20$ & $\geq 4$ & $<20$ & $\geq 4$ & $<20$ & $<20$ \\
\hline Terminal leaflet width (mm): TlW & $<8$ & $\geq 8$ & $<8$ & $\geq 8$ & $<8$ & $\geq 8$ & $<8$ & $<8$ \\
\hline Terminal leaflet width/length: TIW/L & $<0.4$ & $\geq 0.4$ & $<0.4$ & $\geq 0.4$ & $<0.4$ & $\geq 0.4$ & $<0.4$ & $<0.4$ \\
\hline Lateral leaflet length $(\mathrm{mm}) \mathrm{LtL}$ & $\geq 18$ & $\geq 18$ & $\geq 18$ & $<18$ & $<18$ & $\geq 18$ & $\geq 18$ & $\geq 18$ \\
\hline Lateral leaflet width (mm): LtW & $\geq 5$ & $\geq 5$ & $\geq 5$ & $\geq 5$ & $<5$ & $\geq 5$ & $\geq 5$ & $\geq 5$ \\
\hline Lateral leaflet width/length: LlW/L & $<0.32$ & $<0.32$ & $\geq 0.32$ & $\geq 0.32$ & $<0.32$ & $\geq 0.32$ & $\geq 0.32$ & $<0.32$ \\
\hline Terminal leaflet apex shape: TlA & mucronate & mucronate & mucronate & mucronate & mucronate & mucronate & mucronate & hooked \\
\hline Leaf stipule shape: LS & hairy & leafy & leafy & leafy & leafy & leafy & hairy & leafy \\
\hline Stipule length (mm): SL & $\geq 9$ & $<9$ & $<9$ & $<9$ & $<9$ & $<9$ & $\geq 9$ & $<9$ \\
\hline Peduncle length (mm): PdL & $<18$ & $\geq 18$ & $<18$ & $<18$ & $<18$ & $\geq 18$ & $\geq 18$ & $\geq 18$ \\
\hline
\end{tabular}




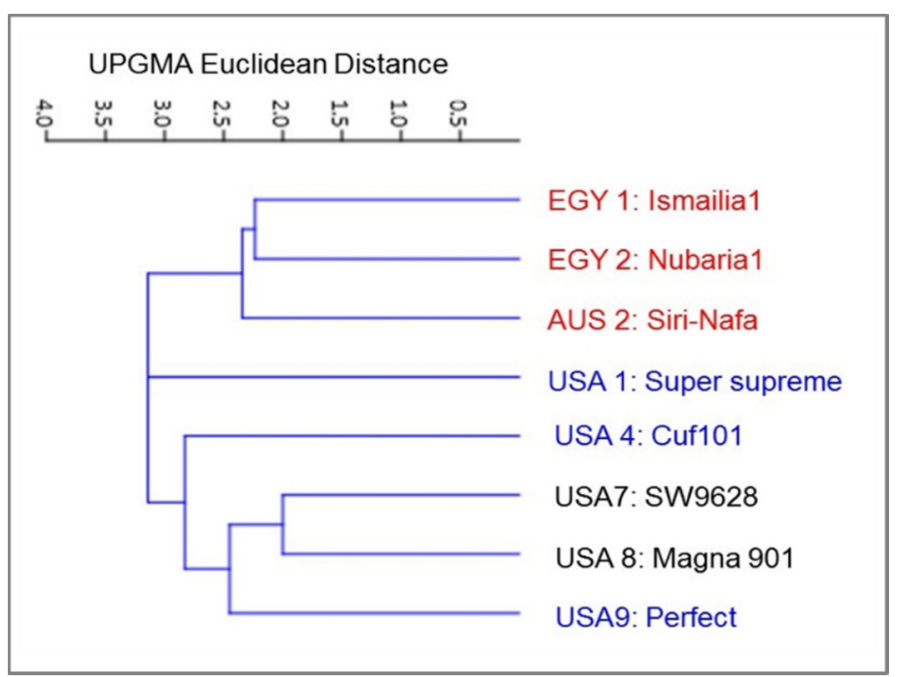

Figure 7. Cluster tree illustrating the genetic distance, based the analysis of 16 morpho-agronomic traits for eight $M$. sativa cultivars using the Euclidean distance and the UPGMA algorithm in the PAST software.

The clustering of the eight cultivars confirmed the close genetic relationship between the two Egyptian M. sativa cultivars. However, AUS2-Siri Nafa was assigned close to these two cultivars, whereas the two cultivars USA1-Super-supreme and USA4-Cuf101 were clearly isolated from a cluster of the other three cultivars, namely, USA7-SW9623, USA8-Magna901 and USA9-Perfect. A PCA biplot, constructed by blotting the PCA 2 and PCA 4, showed the best illustration of the impact of the studied morpho-agronomic traits on the discrimination of the examined cultivars (Figure 8). The affinity of the two Egyptian cultivars and their distinction from the other alfalfa cultivars was most influenced by plant height $(\mathrm{PH})$ and stem number (SN). The distribution of the American cultivars in the biplot was most influenced by the following traits: lateral leaflet width/length (LlW/L), stipule length (SL), lateral leaflet length $(\mathrm{mm})(\mathrm{LtL})$, lateral leaflet width $(\mathrm{mm})(\mathrm{LtW})$, lateral leaflet length $(\mathrm{mm})(\mathrm{LtL})$, and peduncle length (PdL). On the other hand, the distinction of AUS2-Siri Nafa was mostly impacted by the terminal leaflet width (TlW) and terminal leaflet width/length (TlW/L).

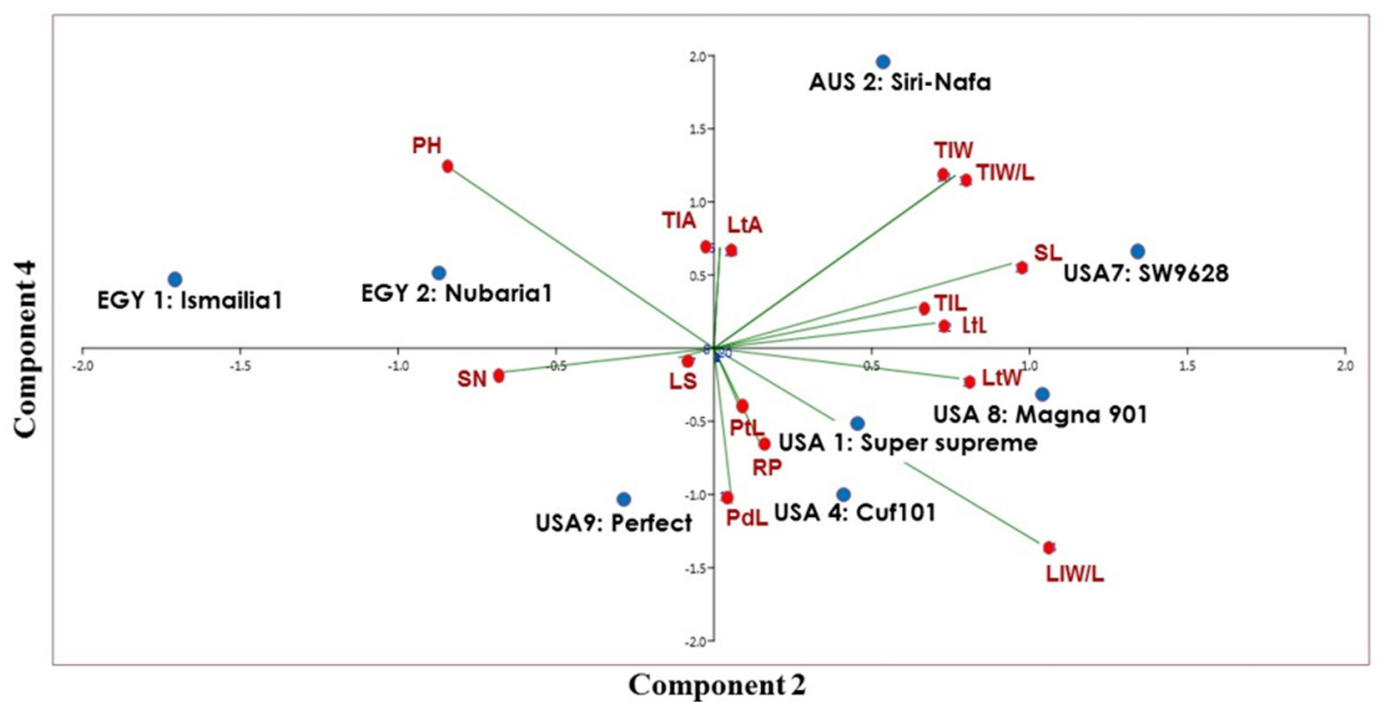

Figure 8. Biplot displays a cluster tree illustrating the genetic distance, based on the analysis of 15 morpho-agronomic traits for eight $M$. sativa cultivars using the Euclidean distance and the UPGMA algorithm in the PAST software. 


\section{Discussion}

In this study, IRAP markers and the chloroplast DNA matK and $\operatorname{trn} \mathrm{H}$ barcodes were used to assess genetic diversity in some M. sativa cultivars currently cultivated in Egypt, USA, and Australia. Genetic diversity has been assessed using 97 markers produced by 11 IRAP primers; with $79.73 \%$ polymorphism and an average of 7.72 markers per primer although this number ranges between 3 for IRAP 4351 and 21 for IRAP 4340. Five primers (IRAP 4334, 4370, 4340, 4342, and 3471) produced 100\% polymorphism indicating highly variable regions in the genome (Mansour 2008). IRAP fingerprinting also resulted in high polymorphism in different species and reflected intraspecific variations in Mastic tree [46]. The high percentage of polymorphism detected in the present study by IRAP may also indicate a high insertional activity for the assessed RTNs in the genome of $M$. sativa cultivars as reported for wheat $[22-24,47]$.

The value of genetic diversity parameters revealed by IRAP markers was used to calculate the genetic diversity of $12 \mathrm{M}$. sativa cultivars using multivariate clustering, PCA, and heatmap analyses indicated that the two Egyptian cultivars and AUS2-Siri-Nafa are distinguished from other cultivars. Close affinity is also clear between the Australian cultivars to each other and the American cultivars to each other with some resemblance between some cultivars as indicated in Figures 2-4, in particular between USA10-Super10 and USA3-Grasis II; USA4-Cuf101 and USA5-Supreme forager, as indicated by cluster analysis (Figure 2); and between USA10-Super10 and USA3-Grasis II, as shown in PCA analysis (Figure 3); between USA10-Super10 and EGY1-Ismailia1; and EGY2-Nubaria1 and AUS4-SuperFast and USA2-Nafa Extra (Figure 4). The differentiation of the studied M. sativa cultivars of different countries may be accounted for by former differences in climatic conditions, which might contribute to increasing the genetic variation between cultivars. The findings based on IRAP marker analyses might be attributable to the instability of RTN insertion events as well as to the environmental conditions $[48,49]$.The high level of IRAP markers polymorphism could relate to the outcrossing and the tetraploid nature of alfalfa $[20,50,51]$.

The present study revealed that $m a t \mathrm{~K}$ is more variable than $t r n \mathrm{H}$ in sequence variability among the tested Medicago cultivars. It has been reported that matK, due to its conservative mode of evolution, is widely used in many phylogenetic studies of flowering plants. It was used to distinguish medicinal plants and validate many herbal products [52,53]. In the current studies, eight alfalfa cultivars were differentiated based on matK sequence variation using five outgroup sequences (Figure 5). The phylogenetic tree generated using five NCBI-extracted matK sequences representing four $M$. sativa subspecies and one of $M$. truncatula supported the outstanding finding of separating the two Egyptian cultivars EGY1-Ismailia1 and EGY2-Nubaria1 along with M. sativa NCBI-extracted matK of M. sativa and its subspecies members as well as USA9-Perfect which was not included in the IRAP experiment. However, EGY2-Nubaria1 was separated with the M. sativa NCBI-extracted matK sequence of the subspecies caerulea, indicating sequence homology between them. In the second clade of four American cultivars, USA4-Cuf101, USA7-SW9623, USA8-Magna901 and USA1-Super supreme grouped with M. truncatula and AUS2-Siri Nafa, and the latter two cultivars shared the two most similar matK sequences.

The phylogenetic tree constructed based on the trn H sequence showed close homology of the eight examined cultivars as all were clearly isolated from the three outgroups (Figure 6). This may be due to the limited sequence variability in $\operatorname{trn} \mathrm{H}$ sequence in the tested cultivars. In this clade, AUS2-Siri-Nafa and the Egyptian cultivars were clearly isolated from the five American ones in agreement with their clustering based on the morpho-agronomic traits. The phylogenetic heatmap analysis of the $t r n \mathrm{H}$ sequence generated also confirmed the distinction of the Egyptian cultivars EGY1-Ismailia1 and EGY2-Nubaria1 and AUS2-Siri Nafa from Australia.

Despite criticisms of using morphological traits to identify plant cultivars or study their genetic variability, they have proven useful in evaluating genetic diversity in alfalfa [33]. The classification of eight cultivars in the current study confirmed the close genetic relationship between the two Egyptian cultivars and AUS2-Siri-Nafa, whereas the two cultivars USA1-Super supreme and USA4-Cuf101 were 
clearly isolated from a cluster of other three American cultivars: USA7-SW9623, USA8-Magna901 and USA9-Perfect. Morphological variability among accessions of 18 non-dormant alfalfa was strongly influenced by leaflet shape, stipule shape, the peduncle, and the petiole length ratio [12]. In the current study, the PCA biplot classification of the studied alfalfa cultivars confirmed the affinity between the two Egyptian cultivars, EGY1-Ismailia1 and EGY2-Nubaria1, and their distinction from the other cultivars, but also indicated resemblance to AUS2-Siri Nafa from Australia. The distinction of the two Egyptian cultivars EGY1-Ismailia1 and EGY2-Nubaria1 agrees with the clustering together of local accessions in Saudi Arabia and their differentiation from other origins. Clusters of local accessions at high similarity sometimes correlated with their collection site and morphological traits [16].

Morphological characters are the external expression of the genotype. The plant habit, stem, leaves, flower, fruit and seeds have been used for classification of alfalfa cultivars based on morphological variation [34,54]. Some of the examined cultivars were characterized by morphological traits [41]. The American cultivar USA8-Magna901, originating from DairyLand, America, has a high forage production, a fall dormancy rating of 9, and good growth in winter with a high resistance to nematodes [55]. USA4-Cuf101 is characterized with a high resistance to cold stress, Fusarium root rot, and root nodule nematodes. Hereby, USA4-Cuf101 is favored for its high forage production, a dormancy rating of 10, and dry climate resistance. Moreover, USA4-Cuf101 is characterized with a high tolerance to Fusarium and Pythophtora [55]. USA4-Cuf101 and USA8-Magna901 showed closer affinities to other American cultivars and a distant relationship to the Egyptian and Australian cultivars. Among the Australian cultivars, AUS2-Siri Nafa is characterized by drought tolerance and resistance to root diseases [55].

\section{Conclusions}

The presented results of genetic variation between the studied alfalfa cultivars, based on IRAP, DNA barcoding and morpho-agronomical traits, are considered as potentially useful sources of genetic information in developing future breeding program(s) and opening up new possibilities of producing M. sativa lines that have high forage quality, productivity and resistance to biotic and abiotic stress conditions. For these objectives, collection and characterization of genetic resources are required for the development of new cultivars.

Supplementary Materials: The following are available online at http://www.mdpi.com/2223-7747/9/8/995/s1: Figure S1: Agarose gel electrophoresis of PCR products showing amplification of DNA loci of matK and trn $\mathrm{H}$ genes in eight $M$. sativa cultivars; Figure S2: PCA scatter diagram illustrating genetic diversity based on the analysis of matK DNA barcoding regions for nine $M$. sativa cultivars by blotting the first two principal components using PAST software; Figure S3: Multivariate heatmap illustrating the genetic diversity of nine M. sativa cultivars (denoted by asterisks in Table 1) and four outgroups, using the module of heatmap of R software based on the matK barcoding sequence and five NCBI-extracted matK sequences belonging $M$. sativa and its subspecies $\mathrm{x}$-varia, glomerate and caerulea, as well as M. truncatula; Figure S4: Multivariate heatmap illustrating the genetic diversity of nine $M$. sativa cultivars (denoted by asterisks in Table 1 ) and four outgroups, using the module of heatmap of $R$ software based on trnH DNA barcoding regions and three NCBI-extracted trnH sequences belonging to $M$. sativa and its subspecies glomerate, and caerulea; Table S1: Similarity matrix among 12 M. sativa cultivars, as computed using Dice's coefficient based on IRAP molecular marker polymorphism; Table S2: Evaluation of matK DNA barcoding region; Table S3: Evaluation of $t r n \mathrm{H}$ DNA barcoding region.

Author Contributions: Conceptualization, N.E.-S.; A.B. and M.I.; methodology, N.E.-S., S.A., S.D.I. and M.I.; experimental analysis, N.E.-S., S.A., S.D.I. and M.I.; data curation, A.B., N.E.-S., S.A., and M.I.; original draft preparation, N.E.-S., S.A., and M.I.; writing-reviewing and editing, A.B., N.E.-S. and M.I.; supervision, A.B. All authors have read and agreed to the published version of the manuscript.

Funding: This research received no external funding.

Acknowledgments: The authors are grateful to the postgraduate studies and research affairs, Faculty of Science, Ain Shams University, Cairo, Egypt, for making all research facilities and materials available to conduct the experimental part. Thanks are extended to Professor Hoda Barakat, professor of Genetics, Faculty of Science, Ain Shams University, for kindly providing alfalfa seeds and keen advice on practical procedures. The authors are also grateful to Alsamman M. Alsamman, Department of Genome Mapping, Agricultural Genetic Engineering Research Institute (AGERI), for advice on the use of R software.

Conflicts of Interest: The authors declare no conflict of interest. 


\section{References}

1. Suttie, J.M. Alfalfa and Relatives: Evolution and Classification of Medicago. By E. Small. Wallingford, UK: CABI (2011), pp. 727, £110.00. Exp. Agric. 2012, 48, 308-309. [CrossRef]

2. Li, X.; Brummer, E.C. Applied Genetics and Genomics in Alfalfa Breeding. Agronomy 2012, 2, 40-61. [CrossRef]

3. Blondon, D.; Marie, S.; Brown, A. Kondorosi, Genome size and base composition in Medicago sativa and M. truncatula species. Genome 1994, 37, 264-270. [CrossRef] [PubMed]

4. Veronesi, F.; Brummer, E.C. Handbook of Plant Breeding: Fodder Crops and Amenity Grasses; Springer: New York, NY, USA, 2010.

5. Annicchiarico, P. Diversity, genetic structure, distinctness and agronomic value of Italian lucerne (Medicago sativa L.) landraces. Euphytica 2006, 148, 269-282. [CrossRef]

6. Tucak, M.; Popović, S.; Čupic, T.; Šimic, G.; Gantner, R.; Meglič, V. Evaluation of alfalfa germplasm collection by multivariate analysis based on phenotypic traits. Rom. Agric. Res. 2009, 26, 47-51.

7. Tucak, M.; Popović, S.; Čupić, T.; Grljušić, S.; Meglič, V.; Jurković, Z. Efficiency of phenotypic and DNA markers for a genetic diversity study of alfalfa. Генетика 2010, 46, 1314-1319. [CrossRef]

8. Bornet, M. Branchard, Nonanchored Inter Simple Sequence Repeat (ISSR) markers: Reproducible and specific tools for genome fingerprinting. Plant Mol. Biol. Rep. 2001, 19, 209-215. [CrossRef]

9. Semagn, K.; Bjørnstad, Å.; Ndjiondjop, M.N. An overview of molecular marker methods for plants. Afr. J. Biotechnol. 2006. [CrossRef]

10. Badr, A. Molecular approaches to plant systematic and evolution. Taeckholmia 2008, 28, 127-167.

11. El-Shazly, H.H.; HAhmed, I.S.; Hamouda, M.M.; Badr, A. Genetic diversity and population structure of the medicinal plant Achillea fragrantissima (Forssk.) Sch. Bip. in the mountains of South Sinai, Egypt. Plant Gene. 2020, 21, 100212. [CrossRef]

12. Collard, B.C.Y.; Mackill, D.J. Start Codon Targeted (SCoT) Polymorphism: A Simple, Novel DNA Marker Technique for Generating Gene-Targeted Markers in Plants. Plant Mol. Biol. Rep. 2009, 27, 86-93. [CrossRef]

13. Mardi, M.; Naghavi, M.R.; Pirseyedi, S.M.; Alamooti, M.K.; Monfared, S.R.; Ahkami, A.H.; Omidbakhsh, M.A.; Alavi, N.S.; Shanjani, P.S.; Katsiotis, A. Comparative assessment of SSAP, AFLP and SSR markers for evaluation of genetic diversity of durum wheat (Triticum turgidum L. var. durum). J. Agric. Sci. Technol. 2011, 13, 905-920.

14. Bagavathiannan, M.V.; Julier, B.; Barre, P.; Gulden, R.H.; van Acker, R.C. Genetic diversity of feral alfalfa (Medicago sativa L.) populations occurring in Manitoba, Canada and comparison with alfalfa cultivars: An analysis using SSR markers and phenotypic traits. Euphytica 2010, 173, 419-432. [CrossRef]

15. Robarts, D.W.H.; Wolfe, A.D. Sequence-Related Amplified Polymorphism (SRAP) Markers: A Potential Resource for Studies in Plant Molecular Biology. Appl. Plant Sci. 2014, 2. [CrossRef] [PubMed]

16. Al-Faifi, S.A.; Migdadi, H.; Al-Doss, A.; Ammar, M.H.; El-Harty, E.H.; Khan, M.A.; Muhammad, J.M.; Alghamdi, S.S. Morphological and molecular genetic variability analyses of Saudi lucerne (Medicago sativa L.) landraces. Crop. Pasture Sci. 2013, 64, 137-146. [CrossRef]

17. Ben Rhouma, H.; Taski-Ajdukovic, K.; Zitouna, N.; Sdouga, D.; Milic, D.; Trifi-Farah, N. Assessment of the genetic variation in alfalfa genotypes using SRAP markers for breeding purposes. Chil. J. Agric. Res. 2017, 77, 332-339. [CrossRef]

18. Wicker, T.; Sabot, F.; Hua-Van, A.; Bennetzen, J.L.; Capy, P.; Chalhoub, B.; Flavell, A.; Leroy, P.; Morgante, M.; Panaud, O.; et al. A unified classification system for eukaryotic transposable elements. Nat. Rev. Genet. 2007, 8, 973-982. [CrossRef]

19. Kalendar, R.; Schulman, A.H. Transposon-Based Tagging: IRAP, REMAP, and iPBS. Adv. Struct. Saf. Stud. 2013, 1115, 233-255. [CrossRef]

20. Mandoulakani, A.B.; Sadigh, P.; Azizi, H.; Piri, Y.; Nasri, S. Comparative assessment of IRAP, REMAP, ISSR, and SSR markers for evaluation of genetic diversity of alfalfa (Medicago sativa L.). J. Agric. Sci. Technol. 2015, 17, 999-1010.

21. Baumel, A.; Ainouche, M.L.; Kalendar, R.; Schulman, A.H. Retrotransposons and genomic stability in populations of the young allopolyploid species Spartina anglica C.E. Hubbard (Poaceae). Mol. Biol. Evol. 2002, 19, 1218-1227. [CrossRef]

22. Nasri, S.; Mandoulakani, B.A.; Darvishzadeh, R.; Bernousi, I. Retrotransposon Insertional Polymorphism in Iranian Bread Wheat Cultivars and Breeding Lines Revealed by IRAP and REMAP Markers. Biochem. Genet. 2013, 51, 927-943. [CrossRef] [PubMed] 
23. Farouji, A.E.; Khodayari, H.; Saeidi, H.; Rahiminejad, M.R. Genetic diversity of diploid Triticum species in Iran assessed using inter-retroelement amplified polymorphisms (IRAP) markers. Biology 2015, 70, 52-60. [CrossRef]

24. Taheri, M.T.; Alavi-Kia, S.S.; Mohammadi, S.A.; Vahed, M.M. Assessment of genetic diversity and relationships among Triticum urartu and Triticum boeoticum populations from Iran using IRAP and REMAP markers. Genet. Resour. Crop. Evol. 2018, 65, 1867-1878. [CrossRef]

25. Guo, Y.; Zhai, L.; Long, H.; Chen, N.; Gao, C.; Ding, Z.; Jin, B. Genetic diversity of Bletilla striata assessed by SCoT and IRAP markers. Hereditas 2018, 155, 35. [CrossRef]

26. Hebert, P.D.N.; Cywinska, A.; Ball, S.L.; Dewaard, J.R. Biological identifications through DNA barcodes. Proc. R. Soc. B Biol. Sci. 2003, 270, 313-321. [CrossRef]

27. Hollingsworth, P.M.; Graham, S.W.; Little, D.P. Choosing and Using a Plant DNA Barcode. PLoS ONE 2011, 6, e19254. [CrossRef]

28. Hajibabaei, M.; Singer, G.A.; Clare, E.L.; Hebert, P.D.N. Design and applicability of DNA arrays and DNA barcodes in biodiversity monitoring. BMC Biol. 2007, 5, 24. [CrossRef]

29. Pei, N.; Chen, B.; Kress, W.J. Advances of Community-Level Plant DNA Barcoding in China. Front. Plant Sci. 2017, 8, 225. [CrossRef]

30. Whitlock, B.A.; Hale, A.M.; Groff, P.A. Intraspecific Inversions Pose a Challenge for the trnH-psbA Plant DNA Barcode. PLoS ONE 2010, 5, e11533. [CrossRef]

31. Madesis, P.; Ganopoulos, I.; Ralli, P.; Tsaftaris, A. Barcoding the major Mediterranean leguminous crops by combining universal chloroplast and nuclear DNA sequence targets. Genet. Mol. Res. 2012, 11, 2548-2558. [CrossRef]

32. Bondok, A. Using DNA Barcoding for Fingerprinting of Two Important Forage Crops Varieties (Alfalfa and Egyptian Clover). J. Agric. Chem. Biotechnol. 2019, 10, 195-201. [CrossRef]

33. Riday, H.; Brummer, E.C. Morphological variation of Medicago sativa subsp. falcata genotypes and their hybrid progeny. Euphytica 2004, 138, 1-12. [CrossRef]

34. Warburton, M.L.; Smith, S.E. Regional Diversity in Nondormant Alfalfas from India and the Middle East. Crop. Sci. 1993, 33, 852-858. [CrossRef]

35. Rumbaugh, M.D.; Graves, W.L.; Caddel, J.L.; Mohammad, R.M. Variability in a Collection of Alfalfa Germplasm from Morocco. Crop. Sci. 1988, 28, 605-609. [CrossRef]

36. Rumbaugh, M.D. Plant Introductions: The Foundation of North American Forage Legume Cultivar Development; John Wiley \& Sons, Inc.: New York, NY, USA, 2015. [CrossRef]

37. Riday, H.; Brummer, E.C.; Moore, K.J. Heterosis of Forage Quality in Alfalfa. Crop. Sci. 2002, 42, $1088-1093$. [CrossRef]

38. Maniatis, T.; Fritsch, E.F.; Sambrook, J. Molecular Cloning: A Laboratory Manual, 2nd ed.; Cold Spring Harb: New York, NY, USA, 1988.

39. Castresana, J. Selection of conserved blocks from multiple alignments for their use in phylogenetic analysis. Mol. Biol. Evol. 2000, 17, 540-552. [CrossRef]

40. Talavera, G.; Castresana, J. Improvement of Phylogenies after Removing Divergent and Ambiguously Aligned Blocks from Protein Sequence Alignments. Syst. Biol. 2007, 56, 564-577. [CrossRef]

41. Moawed, M.M. Evaluation of morphological and anatomical characters for discrimination and verification of some Medicago sativa (L.) Cultivars. Indian J. Agric. Res. 2016, 50. [CrossRef]

42. Ghislain, M.; Zhang, D.; Fajardo, D.; Huamán, Z.; Hijmans, R. Marker-assisted sampling of the cultivated Andean potato Solanum phureja collection using RAPD markers. Genet. Resour. Crop. Evol. 1999, 46, 547-555. [CrossRef]

43. Gilbert, J.E.; Lewis, R.V.; Wilkinson, M.J.; Caligari, P.D.S. Developing an appropriate strategy to assess genetic variability in plant germplasm collections. Theor. Appl. Genet. 1999, 98, 1125-1131. [CrossRef]

44. Powell, W.; Morgante, M.; Andre, C.; Hanafey, M.; Vogel, J.; Tingey, S.; Rafalski, A. The comparison of RFLP, RAPD, AFLP and SSR (microsatellite) markers for germplasm analysis. Mol. Breed. 1996, 2, 225-238. [CrossRef]

45. Hammer, Ø.; Harper, D.A.T.; Ryan, P.D. Past: Paleontological statistics software package for education and data analysis. Palaeontol. Electron 2001, 4, 1-9.

46. Turhan Serttaş, P.; Özcan, T. Intraspecific variations studied by ISSR and IRAP markers in mastic tree (Pistacia lentiscus L.) from Turkey, Trak. Univ. J. Nat. Sci. 2018. [CrossRef] 
47. Kashkush, K.; Feldman, M.; Levy, A. Transcriptional activation of retrotransposons alters the expression of adjacent genes in wheat. Nat. Genet. 2003, 33, 102-106. [CrossRef]

48. Mansour, A. Utilization of genomic retrotransposons as cladistic markers. J. Cell Mol. Biol. 2008, 7, 17-28.

49. Kalendar, R.; Flavell, A.J.; Ellis, T.H.N.; Sjakste, T.; Moisy, C.; Schulman, A.H. Analysis of plant diversity with retrotransposon-based molecular markers. Heredity 2010, 106, 520-530. [CrossRef]

50. Mengoni, A.; Gori, A.; Bazzicalupo, M. Use of RAPD and microsatellite (SSR) variation to assess genetic relationships among populations of tetraploid alfalfa, Medicago sativa. Plant Breed. 2000, 119, 311-317. [CrossRef]

51. Falahati-Anbaran, M.; Habashi, A.A.; Esfahany, M.; Mohammadi, S.A.; Ghareyazie, B. Population genetic structure based on SSR markers in alfalfa (Medicago sativa L.) from various regions contiguous to the centres of origin of the species. J. Genet. 2007, 86, 59-63. [CrossRef]

52. Inglis, P.W.; Mata, L.R.; Da Silva, M.J.; Vieira, R.F.; Alves, R.D.B.; Silva, D.B.; Azevedo, V.C. DNA Barcoding for the Identification of Phyllanthus Taxa Used Medicinally in Brazil. Planta Med. 2018, 84, 1300-1310. [CrossRef]

53. Gao, Z.; Liu, Y.; Wang, X.; Wei, X.; Han, J. DNA Mini-Barcoding: A Derived Barcoding Method for Herbal Molecular Identification. Front. Plant Sci. 2019, 10, 987. [CrossRef]

54. Loumerem, M.; Ferchichi, A.; Haddad, M.; Rahim, M.A.A.; Hajjaji, H. Collection and evaluation of lucerne (Medicago sativa L.) germplasm from oases of Tunisia. Genet. Resour. Crop. Evol. 2007, 54, 1645-1651. [CrossRef]

55. N.A.F.A. (NAFA) Winter Survival, Fall Dormancy \& Pest Resistance Ratings for Alfalfa Varieties, 2014th ed. 2014. Available online: www.alfalfa.org (accessed on 1 May 2020).

(C) 2020 by the authors. Licensee MDPI, Basel, Switzerland. This article is an open access article distributed under the terms and conditions of the Creative Commons Attribution (CC BY) license (http://creativecommons.org/licenses/by/4.0/). 